\title{
Computer Self-Efficacy, Anxiety, and Learning in Online Versus Face to Face Medium
}

\author{
Richard Hauser, Ravi Paul, and John Bradley \\ MIS Department, East Carolina University, Greenville, NC, USA
}

\author{
hauserr@ecu.edu; paulr@ecu.edu; bradleyj@ecu.edu
}

\section{Executive Summary}

The purpose of this research is to examine the relationships between changes to computer selfefficacy (CSE) and computer anxiety and the impact on performance on computer-related tasks in both online and face-to-face mediums. While many studies have looked at these factors individually, relatively few have included multiple measures of these factors concurrently and assessed the effects over a period of time in a realistic environment. Transactional Distance Theory and previous research are used to develop a theoretical model integrating these factors. Transactional distance can be viewed as an outcome of the culture within an educational environment. As such the three transactional distance variables - structure, dialogue, and learner autonomy - may be measured by certain aspects of that culture. Describing the two mediums in terms of transactional distance allowed us to explore the interrelationships between the changes in CSE, Anxiety, and Performance in face-to-face and online classes.

Data are drawn from students in a junior level Management Information Systems (MIS) class at a medium-size public University in the Southeast U.S.A. Classes in both mediums completed a real life computer-based project in which previously validated instruments are used to longitudinally measure perceptions of computer self-efficacy (CSE), computer anxiety, and transactional distance. Partial Least Squares (PLS), a structural equation modeling technique, is used to compare the results of these factors on performance in both the face-to-face and online mediums.

The results show transactional distance was indeed acting as an anxiety-reducing mechanism.

A comparison of differences between mediums suggests that the various aspects of transactional distance influence each differently. The findings highlight the importance of structure and innovation in the online medium while aspects of dialog were shown to be important in the face-toface medium. In effect, the interactive or emotive characteristics of transactional distance were more important in the face-to-face medium, while the structure and individual autonomy aspects were more influential in the online medium. Thus, one implication for face-to-face instructors is the need to continually maintain free-flowing dialog with the students to enhance learning. On the other hand, logical organization is very important in an online medium. Finally, the significance

Material published as part of this publication, either on-line or in print, is copyrighted by the Informing Science Institute. Permission to make digital or paper copy of part or all of these works for personal or classroom use is granted without fee provided that the copies are not made or distributed for profit or commercial advantage AND that copies 1) bear this notice in full and 2) give the full citation on the first page. It is permissible to abstract these works so long as credit is given. To copy in all other cases or to republish or to post on a server or to redistribute to lists requires specific permission and payment of a fee. Contact Publisher@InformingScience.org to request redistribution permission. of the innovation component illustrates the importance of using new techniques and technologies to improve the interaction aspect of online education. Understanding these differences and implementing measures to accommodate these differences could increase teaching effectiveness and ultimately result in improvements in performance on computer-related tasks. 
Keywords: computer self-efficacy, database self-efficacy, computer anxiety, learning, online medium, computer-based performance, transactional distance, classroom culture

\section{Introduction}

The increased use of Internet technology, particularly in distance education has allowed businesses and universities who are constrained by both time and space, to provide more educational opportunities. As online education gains in popularity, it becomes more important to recognize the inherent advantages and disadvantages offered by this medium.

Online education is more than education that occurs over the Internet. It can be viewed as a complex system of knowledge presentation that occurs in an environment devoid of the personal presence of an educator. For example, the online class is structured differently due to the lack of a physical classroom and there are differences in communication channels between student and educator as well as between students. Yet, the result is expected to be a level of student performance that equals the performance of face-to-face students. Therefore, understanding the impact of these differences on the educational process in both mediums has important implications for information systems educators and students alike.

Although empirical research has examined some aspects of online education, there is a lack of comprehensive research that explains how actual performance differs between online and face to face environments. Factors that can influence classroom performance fall into two general categories: individual and environmental. In the individual category, factors have been used such as gender, age, computer experience (Potosy, 2002), computer self-efficacy (Chen, Gully, Whiteman, \& Kilcullen, 2000), and goal orientation (Brown, 2001). Previous research in computing education, the area this study addresses, has identified several personality traits that have an influence on student performance. Two traits that have consistently shown to be influential on performance are perceptions of computer self-efficacy (CSE) and anxiety. Although the results are mixed, most studies agree that anxiety influences CSE, and CSE directly influences performance (Chen, et al., 2000; He \& Freeman, 2010; Saadé \& Kira, 2009).

This research seeks to examine several factors concurrently in an actual IS learning environment, focusing on students performing a database task. Specifically, the study examines the relationships between changes over time in computer self-efficacy (CSE) and computer anxiety, and user performance in both online and face-to-face mediums. The Theory of Transactional Distance is used to frame the environmental differences that may exist between the online and face-to-face environments. The results of this study will contribute to our understanding of the differences between the online and face-to-face mediums and how they need to be manipulated to positively influence student performance in the acceptance and use of technology.

The next section presents a review of the current research on the individual factors CSE and anxiety. Following that, existing research on the Theory of Transactional Distance is examined to frame the environmental differences between the online and face-to-face environments and how they might influence CSE and anxiety. This discussion is then used to develop a theoretical model and hypotheses. The construct operationalization, data collection, data analysis, and model testing results are described in the methodology section after which the authors interpret the findings. Finally, limitations and implications for those teaching in the online and face-to-face environments are discussed.

\section{Theoretical Model Development}

Various factors affect the performance of individual users on an assigned task (Zmud, 1979). Researchers have proposed theories of technology acceptance (Davis, Bacozzi, \& Warsaw, 1989), the Theory of Planned Behavior (Ajzen \& Madden, 1986), Social Cognitive Theory (Bandura, 
1977, 1986), the Theory of Reasoned Action (Ajzen \& Fishbein, 1980) and others that draw from a diverse background of social and psychological research in an attempt to explain the determinants of technology used by individuals. One important construct that has attracted a lot of research attention in this area is Computer Self Efficacy (CSE). CSE, derived from the more general self-efficacy concept arising from Social Cognitive Theory, by its very nature is well suited to study an individual's propensity towards the acceptance of technology and subsequently their performance on a task using the technology (Harrison, Rainer, \& Hochwater, 1997).

\section{Computer Self-Efficacy}

The concept of computer self-efficacy arises from the work of Bandura in the area of Social Cognitive Theory (Bandura, 1977, 1986). Computer self-efficacy (CSE) refers to an individual's belief in his or her ability to apply computer skills to a wider range of tasks (Compeau \& Higgins, 1995a, 1995b).

CSE has been shown to have a direct influence on classroom performance thus the antecedents to CSE might provide a mechanism that can be used to influence it. A number of antecedents and consequents of computer self-efficacy have been studied. Agarwal, Sambamurthy, and Stair (2000) group these antecedents into categories such as social influence (encouragement, management support), demographic variables (experience, age, sex, prior performance), and beliefs (self-conceptions of ability, anxiety). Similarly, consequences are grouped into outcomes (performance, satisfaction, learning), beliefs (affect, anxiety, outcome expectations), and behaviors (use, early adoption). A comprehensive review of the literature can be found in Marakas, Yi, \& Johnson (1998) or Agarwal et al. (2000). Normally CSE is used in the general sense of using a computer to accomplish a multitude of tasks. A common measure for the dependent variable is simply computer use or the frequency of using a computer. CSE was originally conceptualized in the context of general task performance using a computer. CSE has also been included in recent studies in relation to application-specific tasks (Bandura, 1997; Johnson, 2005; Marakas et al., 1998). General CSE refers to a belief that the subject can perform well across a variety of computer tasks. Specific CSE refers to the belief that the subject can perform well using a particular technology such as programming, database development, etc. However, where the subject's experience with a computer is not extremely high, as is the case with many of the subjects in this study, specific CSE explains more variance with regard to predicting performance of the task than general CSE (Johnson \& Marakas, 2000). In an attempt to account for more variance, this study looks not only at CSE in the general sense but also CSE in relationship to a database application

\section{Anxiety}

The second factor, anxiety has been included in technology research since the 1980s (Martin, McCaughtry, Kulinna, Cothran, \& Faust, 2008; Weil, Rosen, \& Sears, 1987). Social Learning Theory suggests that repeated computer exposure without the benefit of anxiety-reducing mechanisms would cause a feedback loop that could result in higher and higher levels of anxiety (Marakas et al., 1998). Some scholars note that anxiety management techniques can be used to control such anxiety (Bloom \& Hautaluruoma, 1990; Weil et al., 1987). Identifying the anxiety management techniques that can be implemented in the educational setting would certainly be of benefit to the educator.

Anxiety is of particular interest because of its relationship to CSE. Anxiety has been shown to have an inverse influence on CSE. It has added value to the educator because it can be manipulated to increase CSE thus increasing the quality of the educational experience as indicated by an increase in performance. Several earlier studies indicate that reduced anxiety does not directly impact performance but does directly influence CSE (Bandura, 1977; Schunk, 1981). Later studies confirm this view (Buche, Davis, \& Vician, 2007; McInerney, McInerney, \& Cothran, 1994; 
Meier, 1985; Mitchell, Hopper, Daniels, \& George, 1994; Raub, 1981; Torkzada \& Koufteros, 1994;). The relationship between anxiety, CSE, and performance is shown in Figure 1.

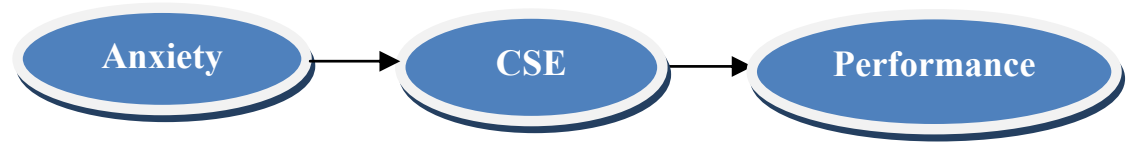

Figure 1. Anxiety, CSE, and Performance.

\section{Transactional distance (Culture)}

Over the past several years researchers have attempted to define the differences between online and face-to-face learning environments. Garrison (1989), Heinze \& Procter (2006), Holmberg (1989), Keegan (1986), Moore (1993), Peters (1983), Smart \& Cappel (2006), and Verduin and Clark (1991) have all made significant theoretical contributions to the understanding of online education. One attempt to unify this previous research was made by Moore (1993). His Theory of Transactional Distance posited that the most important impact on education is pedagogy and not the physical or temporal distance between the teacher and student. As such, the theory can be applied to both distance and face-to-face environments. The variable "transactional distance" is defined as "a psychological and communications space to be crossed, a space of potential misunderstanding between the inputs of instructor and those of the learner" (Moore, 1993, p.23). The extent of transactional distance is a function of three variables: Structure, Dialogue, and Learner Autonomy. Moore (1993) defines them as follows:

A dialogue is purposeful, constructive and valued by each party. Each party in a dialogue is a respectful and active listener; each is a contributor, and builds on the contributions of the other party or parties....The direction of a dialogue in an educational relationship is towards the improved understanding of the student (p. 24).

Structure expresses the rigidity or flexibility of the programme's educational objectives, teaching strategies, and evaluation methods. It describes the extent to which an educational programme can accommodate or be responsive to each learner's individual needs (p. 26).

Learner autonomy is the extent to which in the teaching/learning relationship, it is the learner rather than the teacher who determines the goals, the learning experiences, and the evaluation decisions of the learning programme (p. 31).

According to Moore (1993) education is more effective when the transactional distance is small. He describes the relationships between the three variables and transactional distance as follows. Dialogue and transactional distance (a composite score) are negatively related. When communication between teacher and student is purposeful, constructive, and respectful it decreases the transactional distance between the two individuals which creates an environment in which understanding is more likely to occur. Increasing structure (less responsive to each learner's needs) decreases dialogue and thus increases transactional distance and the likelihood misunderstanding will occur. Giving the student more control over the learning goals and types of evaluations (learner autonomy) increases the probability that understanding will occur (Moore, 1993). Regrettably, an instrument that directly measures Transactional Distance in relation to computer performance could not be found.

One possible proxy for representing Transactional Distance could be classroom culture. Culture is a type of environmental influence that impacts the way people think, work, and interact with one another (Gordon, 1991; Rai, Maruping, \& Venkatesh, 2009; Srite, Thatcher, \& Galy, 2008). As such, transactional distance can be viewed as an outcome of culture in an educational envi- 
ronment. Therefore, structure, dialogue, and learner autonomy may be measured by specific aspects of that culture for which measures are available. Classroom culture was chosen as a surrogate for TD.

One problem with previous research into transactional distance is the lack of construct validity and consistency in measurement (Gorsky \& Caspi, 2005). Studies have used a variety of measures and often only one or two items per construct (see, for example, Bischoff, Biscotier, Kooker, $\&$ Woods, 1996). In an attempt to address this, Newhouse (2001) identified and validated a multidimensional classroom culture instrument with multiple measures for each construct. While several instruments have been developed to measure aspects of classroom culture or climate, NCEI was developed to deal specifically with a computer-supported learning environment. The NCEI instrument includes 56 items on a Likert scale and measures the culture or climate in a computer-supported educational classroom environment along the eight sub-dimensions listed in Table 1 (Newhouse 2001). These items can be mapped onto the dimensions of transactional distance theory as seen in Table 1.

Table 1. Dimensions of Classroom Culture (Newhouse, 2001, p.121) mapped to TDT Dimensions (Moore, 1993)

\begin{tabular}{|c|c|c|}
\hline $\begin{array}{l}\text { TDT Di- } \\
\text { mension }\end{array}$ & $\begin{array}{l}\text { NCEI Dimen- } \\
\text { sion }\end{array}$ & NCEI Dimension Description \\
\hline Dialogue & Involvement & $\begin{array}{l}\text { The extent to which students have attentive interest in class activities and } \\
\text { participate in discussions. The extent to which students do additional } \\
\text { work on their own and enjoy the class. }\end{array}$ \\
\hline Dialogue & Affiliation & $\begin{array}{l}\text { The level of friendship that students feel for each other, that is, the extent } \\
\text { to which they help each other with homework, get to know each other } \\
\text { easily, and enjoy working together. }\end{array}$ \\
\hline Dialogue & $\begin{array}{l}\text { Teacher Sup- } \\
\text { port }\end{array}$ & $\begin{array}{l}\text { The amount of help, concern, and friendship which the teacher directs } \\
\text { toward the students. The extent to which the teacher talks openly with } \\
\text { students, trusts them, and is interested in their ideas. }\end{array}$ \\
\hline Dialogue & Group Work & $\begin{array}{l}\text { The extent to which students are able to work collectively in class on } \\
\text { tasks and activities assigned by the teacher. }\end{array}$ \\
\hline $\begin{array}{l}\text { Learner } \\
\text { Autonomy }\end{array}$ & Competition & $\begin{array}{l}\text { The emphasis placed on students' competing with each other for grades } \\
\text { and recognition. An assessment of the difficulty of achieving good grades } \\
\text { is included. }\end{array}$ \\
\hline $\begin{array}{l}\text { Learner } \\
\text { Autonomy }\end{array}$ & Innovation & $\begin{array}{l}\text { How much students contribute to planning classroom activities, and the } \\
\text { amount of unusual and varying activities and assignments planned by the } \\
\text { teacher. The extent to which the teacher attempts to use new techniques } \\
\text { and encourages creative thinking. }\end{array}$ \\
\hline Structure & $\begin{array}{l}\text { Order and Or- } \\
\text { ganization }\end{array}$ & $\begin{array}{l}\text { The emphasis on student behaving in an orderly and polite manner and on } \\
\text { the overall organization of assignments and classroom activities. }\end{array}$ \\
\hline Structure & Teacher Control & $\begin{array}{l}\text { How strictly the teacher is in enforcing the rules, and the severity of pun- } \\
\text { ishment for rule infractions. }\end{array}$ \\
\hline
\end{tabular}


Given that this instrument was developed specifically for a computer-supported learning environment and the research task for this study is the performance of a database task, it would seem to be ideal for measuring the culture in this study. The NCEI was used to measure transactional distance.

Various factors impact the performance of individual students on a computer related task. Previous research has identified both computer self-efficacy and computer anxiety as having a significant effect on performance (Newhouse, 2001; Thatcher \& Perrewe, 2002). The focus of this research, however, is to better understand the level of influence Transactional Distance has on anxiety in order to explore the possibility of using TD to identify anxiety management techniques.

\section{Theoretical Model and Hypotheses}

As discussed previously, existing research has identified several factors to be important in influencing an individual's performance of a computer related task. Because Transactional Distance describes an environment in which education is effective and previous research has clearly demonstrated the positive influence a decrease in Anxiety has on the effectiveness of the educational process, we presumed that a reduction in transactional distance would act as an anxiety management technique and reduce anxiety. This is shown in the general model in Figure 2. This exploratory research is aimed at examining the relationships among these factors in the two mediums.

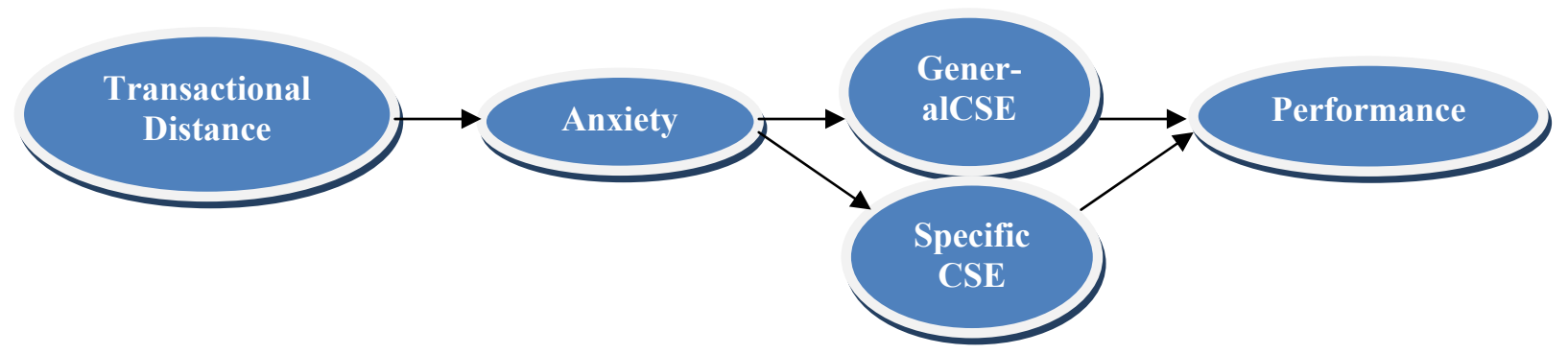

Figure 2. Research Model - Theoretical Model

\section{Computer Self-Efficacy}

H1.1: General computer self-efficacy will have a positive influence on performance in both the online and face-to-face classes

H1.2: Database specific self-efficacy will have a positive influence on performance in both the online and face-to-face classes

Both general and specific CSE were measured at the beginning and at the end of the class resulting in a difference score (post-measure minus pre-measure) that expressed the increase in CSE during the class. The preponderance of research reports the positive influence of CSE on performance (for example see Harrison et al., 1997). The research task that was performed by the subjects was a complex task using a new database technology. Specific CSE was expected to have a stronger influence than general CSE due to the central role the new database technology played in the performance of the task. Theory would suggest that as the students became more proficient with the new technology, their CSE would increase. Thus, a positive change in CSE would be an indicator of a proficient learner who would perform well in either medium.

\section{Anxiety}

H2.1: Anxiety will have a negative influence on general and specific self-efficacy. 
Early studies show that reductions in anxiety that improve CSE can improve performance (Bandura, 1977; Schunk, 1981). Many studies, however, have been inconclusive regarding the effect of anxiety on CSE and performance (Beckers \& Schmidt, 2001) and this therefore needs further discussion.

\section{Transactional Distance}

H3.1 Transactional Distance, as measured by the New Classroom Environment Instrument, will have a positive influence on anxiety in both environments.

If the theory is correct, education is more effective when the transactional distance is small. Specifically, increasing dialogue (Involvement, Affiliation, Teacher Support, Group Work) and decreasing structure (Order and Organization, Teacher Control) should reduce transactional distance and facilitate learning by decreasing anxiety. Similarly increases in learner autonomy (Competition, Innovation) should also reduce transactional distance, again reducing anxiety.

\section{Methodology}

\section{The Sample}

The data were drawn from students in a junior level MIS class at a medium-size public University in the Southeast USA. Over two semesters, a total of 205 usable questionnaires were collected in the face-to-face classes, while the online classes yielded 35. A greater number of online subjects was desired but the study was forced to completion by a change in the use of the database software in the course. The sample consisted of 129 males and 111 females with an average age of 22 years. Students majoring in all areas of business (Accounting, Marketing, MIS, etc.) were represented with an average GPA of 3.1.

\section{Measures}

In both mediums, data collection took place in two phases. First transactional distance, as measured by the New Classroom Environment Instrument (NCEI), was administered to all students at the beginning of the semester. In addition, the anxiety and self-efficacy instruments were administered to establish a baseline. Ten weeks later, after transactional distance had been given an opportunity to develop and have an effect on the students, the instruments were administered again. Concurrently, students were given a hands-on database test utilizing Microsoft Access to measure their individual performances. They were required to complete database tasks within a set time frame. Inter-rater reliability on the scoring of this performance was $92 \%$.

Questionnaires were used to measure anxiety, transactional distance, and computer self-efficacy. During the second data collection, the (NCEI) was used to assess aspects of transactional distance (Newhouse, 2001). Both general (CSE) and database-specific self-efficacy (DBSE) were measured using Compeau and Higgins' (1995b) 10-item instrument. The original instrument was modified for the database portion while care was taken to remain true to the foundational theory. Anxiety scores were measured using the Computer Anxiety Scale (CAS). In the data analysis, CSE and anxiety were measured by the difference between the two data collections. The use of previously validated instruments borrowed from the literature is a commonly accepted practice in IS literature (Marakas, Johnson, \& Clay, 2007). In the face-to-face medium data collection was done with a paper and pencil survey forms, while in the online class, the questionnaire was computerized. Performance was measured by grades achieved in a hands-on exam that covered database tasks.

The NCEI was originally designed to measure the environment of a face-to-face class so several of the questions were inappropriately worded for the online medium and needed to be adjusted. 
Since each question was derived from one of the eight environmental factors (see Table 1), the wording was readily modified to fit the online medium while staying true to the original intent of that question. For example, the question, "Students don't take part in class discussions or activities" is a measure of Involvement which is defined as the extent to which students have attentive interest in class activities and participate in discussions. In this study, students used classroom management software (Blackboard) to communicate with the teacher and with other students. In Blackboard, questions were posted to the Discussion Board by the teacher, then each student posted his/her responses resulting in an online discussion that is not unlike a discussion that would occur in a face-to-face classroom. In the online medium, students would demonstrate their involvement in class through the use of the email, chat session, discussion board forums and file exchange functionality built into the software. Therefore, this question was modified to read, "Students don't take part in online discussions or activities". Another example was the question, "Students get into trouble with the teacher for talking when they are not supposed to." This measure of Teacher Control - how strictly the teacher is in enforcing the rules and the severity of punishment for rule infractions - was modified to, "Students get into trouble with the teacher for inappropriate posts to the discussion board." Of the fifty-six questions, only fourteen had to be modified and these were spread across the eight measures so the responses to any one of the eight measures could not be distorted by modifications to one or two of the seven questions for that measure.

\section{Results and Analysis}

Given the disparity of sample sizes between the face-to-face and online mediums, Partial Least Squares (PLS) was selected as appropriate to test the model. PLS uses a least squares estimation procedure, allowing the user to represent both formative and reflective latent constructs, with minimum demands on scales, sample size, or assumptions (Yi \& Davis, 2003). Thus, PLS is the most appropriate structural equation modeling tool for this situation.

Each of the following models was validated as follows. First internal consistency was established by obtaining a composite reliability of 0.7 or higher. Second, convergent validity was adequate since the square root of the average variance extracted (AVE) was 0.7 or better for all latent variables. Finally, an examination of discriminate validity shows that the standardized variable scores are highly correlated with their appropriate latent construct and not correlated with others. In addition, the square root of the AVE was greater than the correlations between any latent variables.

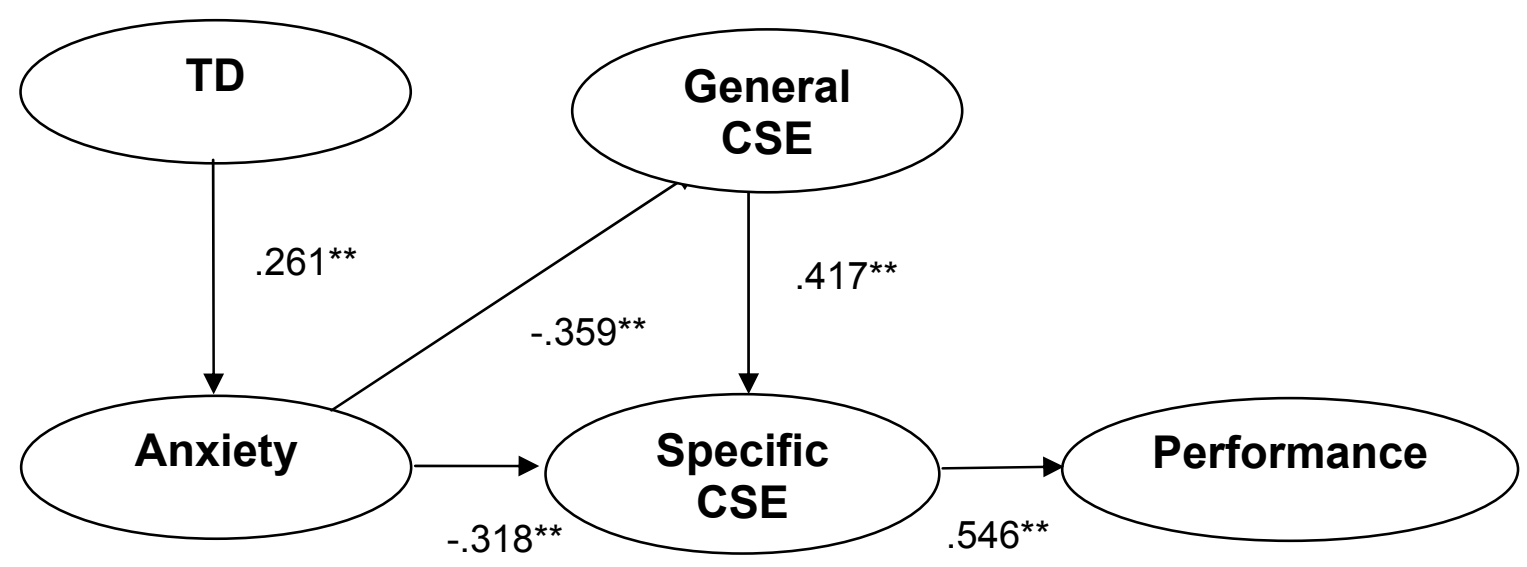

Figure 3. Face-to-Face PLS Model **sig at the .001 level 
The results of the PLS analysis can be seen in Figures 3 and 4. In addition, the PLS analysis allowed the general and specific CSE variables to be broken into two separate variables, enabling one to investigate the relationships between them. Indeed this method of modeling allowed a much richer understanding of the theoretical model. Anxiety was found to be directly negatively related to both general and specific self-efficacy in the face-to-face medium, but only to general self-efficacy in the online medium.

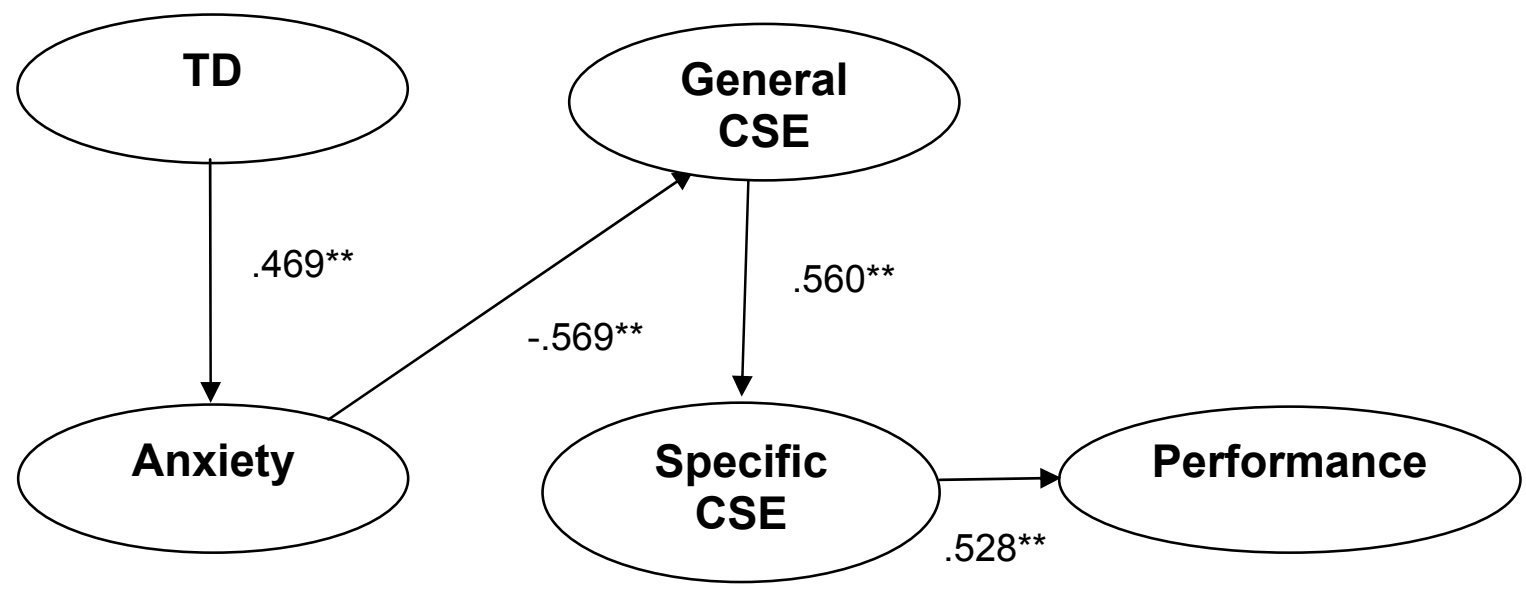

Figure 4. Online PLS Model $* *$ sig at the .001 level

In both mediums, general self-efficacy is positively related to specific self-efficacy. Similarly, specific self-efficacy is positively related to performance in both.

It appears from this analysis that transactional distance directly impacts anxiety. One of the more interesting results lies in which components of transactional distance were found to be significant indicator variables between the face-to-face and online mediums. The PLS technique requires identifying factors that have a significant impact on the latent variables. In the face-to-face medium 5 of the 8 components of the New Classroom Environment Instrument were found to be significant at the .05 level: Involvement, Affiliation, Teacher Support, Group Work, and Order and Organization. In the online medium, however, only Order and Organization and Innovation were found to be significant indicator variables (.05). This has interesting implications for teaching, especially in the online medium.

\section{Discussion}

The purpose of this research was to compare the relationships between computer anxiety, transactional distance, computer self-efficacy (CSE), and user performance in both online and face-toface mediums. This was accomplished using a longitudinal study to evaluate a theoretical model. The results were analyzed using structural equation modeling. Support was found in varying degrees for all three groups of hypotheses.

First, in regard to hypotheses 1.1 and 1.2, higher computer self-efficacy scores appear to be related to higher performance scores. In both mediums, general CSE was positively correlated with specific CSE, and specific CSE was positively correlated with performance. These findings generally confirm previous research (Buche et al., 2007), however this is important in that this study used actual performance. This objective measure of performance provided stronger empirical evidence than previous works using perception-based measures (Potosky, 2002). 
Second, examining hypothesis 2 , anxiety levels do seem to be related to self-efficacy scores. The analysis shows that in the face-to-face medium anxiety is negatively related to both general and specific CSE. In the online medium the relationship is slightly different with anxiety being negatively correlated only with specific CSE. Assuming the small sample size did not materially influence the results, the data emphasizes the importance of managing anxiety in a classroom setting (Buche et al., 2007).

Finally, regarding hypothesis 3 , transactional distance relationships are statistically significant in both mediums. In both the face-to-face and online environments transactional distance is positively related to anxiety. Reducing transactional distance reduces anxiety, which then improves general CSE in both environments. In addition the reduction in anxiety also improves specific CSE in the face-to-face environment. Performance is improved is both cases.

Finally, from an instructional perspective, one of the more interesting findings was that the significant indicator variables for the transactional distance construct varied between the face-to-face and online mediums. In the online medium, only Order and Organization and Innovation were found to be significant. In effect, the interactive or emotive characteristics of transactional distance were not significant in the online medium, while the structure and individual autonomy aspects were. The opposite was true for the face-to-face medium. As one would expect, online students who must meet class requirements without face-to-face, personal interactions with their instructor must depend heavily on the organization and completeness of the class material. Faceto-face students, on the other hand, depend heavily on personal interactions with their instructor in class and during office hours.

\section{Limitations}

Gathering data from students is always a weakness if the intent is to generalize the findings to the business organization. Locke (1986) argues for the appropriateness of generalizing such research. He states:

... The evidence indicates that a detailed, point-by-point similarity with respect to subjects, tasks, settings, and so forth is not necessarily required in order to achieve generalizability. Both college students and employees appear to respond similarly to goals, feedback, incentives, participation, and so forth, perhaps because the similarities among these subjects (such as in values) are more crucial than their differences. (Locke, 1986, p.6)

In this case, a very realistic task was used to compensate in a small way for this weakness. A major shortcoming of the study was the size of the online class data. An attempt was made to address this using an appropriate statistical tool, PLS.

\section{Implications and Conclusions}

This study was designed to allow several conclusions to be drawn. One of the primary strengths of this study was its longitudinal nature allowing pre- and post- measurements to be taken. Almost every study in the anxiety/CSE literature uses a single measure. Instead of knowing that at a fixed point in the study the subjects recorded a high or low level of anxiety, taking two measures reveals whether the anxiety (and CSE) either increased or decreased during the course. Pairing this with the knowledge that a transactional distance was developing during that same time frame, the significant positive relationship between the changes in anxiety and the classroom culture score leads to the conclusion that transactional distance was acting as an anxiety-reducing mechanism. 
Another distinctive component of this study is the use of an objective performance measure. Instead of self-reported impressions, beliefs, perceptions, etc., as is done in most studies, the performance measure in this study was an objective measurement of questions concerning a significantly difficult task.

As discussed previously, a comparison of differences between mediums suggests that the various aspects of transactional distance influence each differently. Transactional distance theory (Moore, 1993) posits that three primary descriptive variables, - interaction, structure, and autonomy, - provide a framework for distance education. While autonomy relates mostly to individual differences between students, interaction and structure are variables that can be affected by the design of the instruction material and the innovativeness of the techniques used by the instructor to promote critical thinking. It should be noted that in Moore's model structure refers more to rigidity. The Order and Organization used as a component of structure in this study was not rigidity but more a measure of how logically the course was laid out.

The findings highlight the importance of structure and innovation in the online medium while aspects of dialog were shown to be important in the face-to-face medium. In effect, the interactive or emotive characteristics of transactional distance were more important in the face-to-face medium, while the structure and individual autonomy aspects were more influential in the online medium. Thus from a pragmatic perspective, one implication for face-to-face instruction is the need to continually maintain free-flowing dialog with the students to enhance learning.

In the online environment, the results first show the importance of logical organization highlighting the importance of structure and innovation. The significance of the innovation component illustrates the importance of using new techniques and technologies to improve the interaction aspect of online education. Understanding these differences and implementing measures to accommodate these differences should increase teaching effectiveness and ultimately result in improvements in performance on computer-related tasks.

In conclusion, this research has shown that there are differences in the relative significance of various factors in the online and face-to-face mediums. Instituting programs that recognize the significance of structure and innovation in the online medium may improve the efficiency and effectiveness of online education.

\section{References}

Agarwal, R., Sambamurthy, V., \& Stair, R. (2000). Research Report: The evolving relationship between general and specific computer self-efficacy-An empirical assessment. Information Systems Research, 11(4), 418-430.

Ajzen, I., \& Fishbein, M. (1980). Understanding attitudes and predicting social behavior. Englewood Cliffs, N.J.: Prentice Hall.

Ajzen, I., \& Madden, T. J. (1986). Prediction of goal-directed behavior: Attitudes, intentions, and perceived behavioral control. Journal of Experimental Social Psychology, 22(5), 453-474.

Bandura, A. (1977). Social learning theory. Englewood Cliffs, NJ: Prentice Hall.

Bandura, A. (1986). Social foundations of thought and action - A social cognitive theory. Englewood Cliffs, NJ: Prentice Hall.

Bandura, A. (1997). Self-Efficacy: The exercise of control. New York: W. H. Freeman.

Beckers, J. J., \& Schmidt, H. G. (2001). The structure of computer anxiety: A six-factor model. Computers in Human Behaviour, 17(1), 35-49. 
Bischoff, W. R., Biscotier, S., Kooker, B., \& Woods, L. (1996). Transactional distance and interactive television in the distance education of health professionals. The American Journal of Distance Education, $10(3), 4-19$.

Bloom, A. J., \& Hautaluruoma, J. E. (1990). Anxiety management training as a strategy for enhancing computer user performance. Computers in Human Behaviour, 6(4), 123-134.

Brown, K. G. (2001). Using computers to deliver training. Personnel Psychology, 54(2), 271-296.

Buche, M. W., Davis, L. R., \& Vician, C. (2007). A longitudinal investigation of the effects of computer anxiety on performance in a computing-intensive environment. Journal of Information Systems Education, 18(4), 415-423.

Chen, G., Gully, S. M., Whiteman, J. A., \& Kilcullen, R. N. (2000). Examination of relationships among trait-like individual differences, state-like individual differences, and learning performance. Journal of Applied Psychology, 85(6), 835-847.

Compeau, D., \& Higgins, C. (1995a). Application of social cognitive theory to training for computer skills. Information Systems Research, 6(2), 118-143

Compeau, D., \& Higgins, C. (1995b), Computer Self-Efficacy: Development of a measure and initial test. MIS Quarterly, 19(2), 189-211.

Davis, F., Bacozzi, R., \& Warsaw, P. (1989). User acceptance of computer technology: A comparison of two theoretical models. Management Science, 35(8), 982-1003.

Garrison, D. R. (1989). Understanding distance education: A framework for the future. London: Routledge.

Gordon, G. G. (1991). Industry determinants of organizational culture. The Academy of Management Review, 16(2), 396-415.

Gorsky, A., \& Caspi, A. (2005). A critical analysis of transactional distance. The Quarterly Review of Distance Education, 6(1), 1-11.

Harrison, A. W., Rainer, R. K., \& Hochwrter, W. A. (1997). Testing the self-efficacy-performance linkage of social-cognitive theory. The Journal of Social Psychology, 137(1), 79-87.

He, Jun, \& Freeman, Lee. (2010). Understanding the formation of general Computer Self-Efficacy. Communications of the Association for Information Systems, 26(12), 225-244.

Heinze, A., \& Procter, C. (2006). Online communication and information technology education. Journal of Information Technology Education, 5, 235-249. Retrieved from http://www.jite.org/documents/Vol5/v5p235-249Heinze156.pdf

Holmberg, B. (1989). Theory and practice of distance education. London: Routledge.

Johnson, R. D. (2005). An empirical investigation of sources of application specific computer self-efficacy and mediators of the efficacy - performance relationship. International Journal of Human - Computer Studies, 62, 737-758.

Johnson, R. D., \& Marakas, G. M. (2000). The role of behavioral modeling in computer skills acquisition: Toward refinement of the model. Information Systems Research, 11(4), 403-417.

Keegan, D. (1986). The foundations of distance education. London: Croom Helm.

Locke, E. A. (1986). Generalizing from laboratory to field settings: Research findings from industrialorganizational psychology, organizational behavior, and human resource management. Lexington, MA: Lexington Books.

Marakas, G. M., Johnson, R. D., \& Clay, P. F. (2007). The evolving nature of the computer self-efficacy construct: An empirical investigation of measurement construction, validity, reliability and stability over time, Journal of the Association for Information Systems, 8(1), 16-46. 
Marakas, G. M., Yi, M. Y., \& Johnson R. D. (1998). The multilevel and multifaceted character of Computer Self-Efficacy: Toward clarification of the construct and an integrative framework for research. Information Systems Research, 9(2), 126-163.

Martin, J., McCaughtry, N., Kulinna, P., Cothran, D., \& Faust, R. (2008). The effectiveness of mentoringbased professional development on physical education teachers' pedometer and computer efficacy and anxiety. Journal of Teaching in Physical Education, 27, 68-82.

McInerney, V., McInerney, D. M., \& Sinclair, K. E. (1994). Student teachers, computer anxiety and computer experience. Journal of Educational Computing Research, 11(1), 177-189.

Meier, S. (1985). Computer aversion. Computers in Human Behaviour, 1(1), 171-179.

Mitchell, T.R., Hopper, H., Daniels, D., \& Geoge, F.J. (1994). Predicting self efficacy and performance during skill acquisition. Journal of Applied Psychology, 79(4), 506-517.

Moore, M. (1993). Theory of transactional distance. In D. Keegan (Ed.), Theoretical principles of distance education (pp. 22-38). Routledge.

Newhouse, C. P. (2001). Development and use of an instrument for computer-supported learning environments. Learning Environments Research, 4, 115-138.

Peters, O. (1983). Distance teaching and industrial production: A comparative interpretation in outline. In D. Sewart, D. Keegan, \& B. Holmberg (Eds.), Distance education: International perspectives (pp. 95113). London: Croom-Helm.

Potosky, D. (2002). A field study of computer self-efficacy beliefs as an outcome of training: The role of computer playfulness, computer knowledge, and performance during training. Computers in Human Behaviour, 18(3), 241-255.

Rai, A., Maruping, L. M., \& Venkatesh, V. (2009). Offshore information systems project success: The role of social embeddedness and cultural characteristics. MIS Quarterly, 33(3), 617-641.

Raub, A. (1981). Correlates of computer anxiety in college students. Dissertation Abstracts International, $42,4775-4785$.

Saadé, R. G., \& Kira, D. (2009). Computer anxiety in E-Learning: The effect of computer self-efficacy. Journal of Information Technology Education, 8, 177-191. Retrieved from http://www.jite.org/documents/Vol8/JITEv8p177-191Saade724.pdf

Schunk, D. (1981). Modeling and attributional effects on children's achievement: A self-efficacy analysis. Journal of Educational Psychology, 73(1), 93-105.

Smart, K., \& Cappel, J. (2006). Students' perceptions of online learning: A comparative study. Journal of Information Technology Education, 5, 201-219. Retrieved from http://www.jite.org/documents/Vol5/v5p201-219Smart54.pdf

Srite, M., Thatcher, J. B., \& Galy, E. (2008). Does within-culture variation matter? An empirical study of computer usage. Journal of Global Information Management, 16(1), 1-25.

Thatcher, J., \& Perrewe, P. (2002). An empirical examination of individual traits as antecedents to computer anxiety and computer self-efficacy. MIS Quarterly, 26(4), 381-398.

Torkzada, G., \& Koufteros, X. (1994). Factorial validity of a computer self efficacy scale and the impact of computer training. Educational and Psychological Measurement, 54(3), 813-821.

Verduin, J. R., \& Clark, T. A. (1991). Distance education: The foundations of effective practice. San Francisco: Jossey-Bass.

Weil, M., Rosen, L., \& Sears, D. (1987). The computerphobia reduction program: Year 1. Program development and preliminary results. Behaviour Research Methods, Instrumentation and Computers, 19(2), 180-184.

Yi, M., \& Davis, F. (2003). Developing and validating an observational learning model of computer software training and skill acquisition. Information Systems Research, 14(2), 146-169. 
Zmud, R. W. (1979). Individual differences and MIS success: A review of the empirical literature. Management Science, 25(10), 966-979.

\section{Biographies}

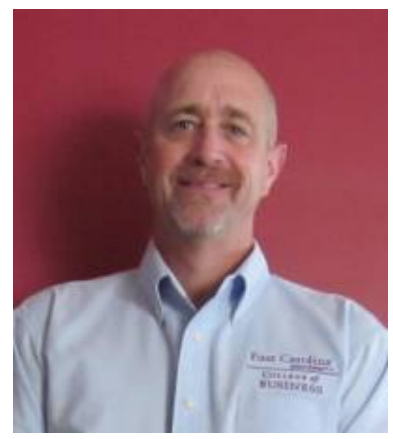

Richard Hauser is associate professor and Chair of the Management Information Systems Department at East Carolina University. He received his Ph.D. in Management Information Systems from Florida State University. His research in information systems, quality, and organizational behavior has appeared in academic journals such as Journal of Computer Information Systems, Accounting, Management, and Information Technologies, Information Resources Management Journal, and Expert Systems with Applications.

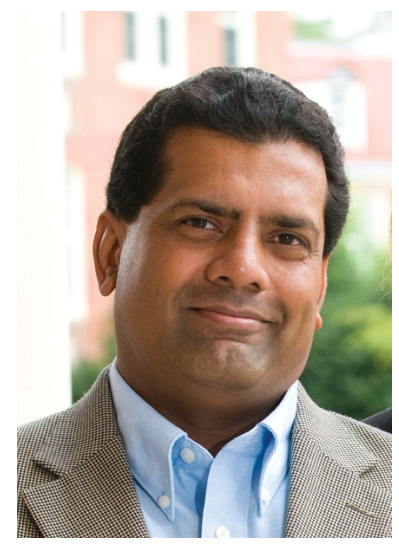

Ravi Paul, Ph.D. is Associate Professor of Management Information Systems in the College of Business at East Carolina University. Ravi earned both his M.S. and Ph.D. in Industrial Management from Clemson University after completing his B.S. in Mechanical Engineering from Bangalore University. His research has been published in journals such as the Requirements Engineering Journal, Information and Management and the Journal of Computer Information Systems, as well as in conference proceedings such as HICSS, AIS and DSI. Prior to teaching, Ravi worked for 12 years in the IT industry, holding technical and managerial positions in systems analysis, design, development, and administration.

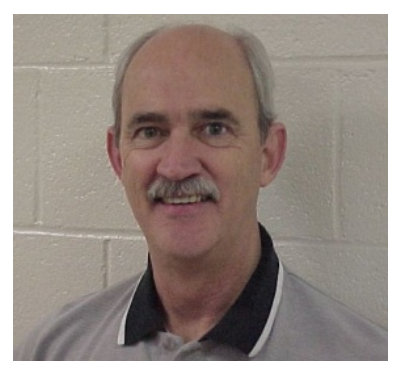

John H. Bradley is a Professor of Management Information Systems at East Carolina University. His research interests are expert systems, case-based reasoning, team performance, and IS implementation and organizational impact. Dr. Bradley has published in journals such as Expert Systems with Applications, Heuristics, Small Group Research, Information \& Management, Journal of Computer Information Systems, Journal of Knowledge Management, and others. 